\title{
Predictors of Fetal Macrosomia Among Women Delivering at a Tertiary Hospital in Tanzania: A Case Control Study
}

Emmanuel Imani Ngadaya ( $\sim$ ngadayaemmanuel@gmail.com )

University of Dodoma College of Health and Allied Sciences: The University of Dodoma College of Health Sciences https://orcid.org/0000-0001-9040-2844

Dr. Maria Angelica Rweyemamu ( $\nabla$ mcbyera@gmail.com ) https://orcid.org/0000-0002-3187-7185

Proffesor Ipyana Hudson Mwampagatwa

Dr. Athanase Gervase Lilungulu

\section{Research Article}

Keywords: Macrosomia, Predictors

Posted Date: June 2nd, 2021

DOl: https://doi.org/10.21203/rs.3.rs-498898/v2

License: (1) (1) This work is licensed under a Creative Commons Attribution 4.0 International License. Read Full License 


\section{Abstract}

Purpose: The study aimed at assessing predictors of fetal macrosomia at Iringa Regional Referral hospital in Tanzania. It is currently challenging to predict fetal macrosomia before delivery which possess women to an increasing risk of sustaining adverse maternal or fetal outcomes.

Methods: A case-control study design in which cases were women who delivered babies weighing $\geq$ $4000 \mathrm{~g}$ while controls were those who delivered babies weighing $2500 \mathrm{~g}$ to $3500 \mathrm{~g}$. Purposive sampling technique was employed to recruit both controls and cases. A total of 216 participants were included. This was an unmatched case control study. SPSS version 25 software program was used for data entry and analysis. Chi-squared test, P-value, unadjusted and adjusted logistic regression were used to determine statistical significant.

Results: Predictors of fetal macrosomia at Iringa Regional Referral hospital were advanced gestation age $(A O R=8.10,95 \% \mathrm{Cl} 3.66-17.91, p=<0.0001)$ and diabetes mellitus during pregnancy ( $A O R=14.94,95 \% \mathrm{Cl}$ $1.60-39.91, p=0.0178)$.

Conclusion: Women with advanced gestation age and diabetes mellitus during pregnancy are at an increased risk of delivering a macrosomic baby. Assessing predictors of fetal macrosomia will enable early prediction and intervention of women with fetal macrosomia hence preventing further maternal and fetal adverse outcomes.

\section{Introduction}

Fetal macrosomia has been linked to increasing nutritional status and the prevalence differs according to ethnicity [1], [2]. It is a birth weight of $\geq 4000 \mathrm{~g}$ or birth weight greater than the 90th percentile at birth [3]. So far the largest recorded birth weight worldwide was in 1894 in Ohio USA which was $10.78 \mathrm{~kg}[4]$.

The worldwide prevalence of fetal macrosomia is $0.5 \%$ to $15 \%$ of all pregnancies [5], [6]. The prevalence in developed countries ranges from $15-20 \%$ due to increasing nutritional intake, obesity and diabetes mellitus [2]. In developing countries specifically in Africa, the prevalence ranges from $2 \%$ to $9 \%$ and the reasons for this prevalence are multiparity and variations in maternal weight gain and height during pregnancy [2], [7]-[9].

The studied predictors of fetal macrosomia so far includes a previous history of delivering a macrosomic baby [10]. Other predictors include multiparty, male gender of the fetus, uncontrolled diabetes mellitus, gestational diabetes, gestational age, maternal weight gain during pregnancy (over nutrition), parental height, post term pregnancy and ethnicity [2], [7], [11], [12]. Fetal macrosomia has been linked to adverse maternal fetal outcomes of worst is postpartum hemorrhage as the leading cause of maternal mortality and neonatal death [7], [13].

Predicting fetal macrosomia in a clinical setting is a challenge in developing countries. The gold standard for diagnosing fetal macrosomia is magnetic resonant imaging (MRI) which is rarely available at many 
facilities in developing countries [14]. Clinical examination (Leopard maneuvers) is less accurate and obstetric ultrasound has been observed to be substandard compared to magnetic resonant imaging (MRI) [14], [15].

This study aimed at assessing the predictors of fetal macrosomia at Iringa Regional Referral Hospital in Tanzania.

\section{Methodology}

\section{Study design and duration}

A hospital-based analytical case-control study design involving pregnant women and their newborns at Iringa Regional Referral Hospital from June to December 2020.

\section{Study area}

This study was conducted in the department of Obstetrics and Gynecology at Iringa Regional Referral Hospital in Iringa Region situated in the Southern Highland of Tanzania.

\section{Study population}

The study involved term ( $\geq 37$ weeks of gestation) singleton pregnant women attending Iringa Regional Referral Hospital for delivery.

\section{Inclusion criteria}

All term ( $\geq 37$ weeks of gestation age) pregnant women. Women delivering $\geq 4000 \mathrm{~g}$ were considered as cases and those delivering $2500 \mathrm{~g}$ to $3500 \mathrm{~g}$ were considered as controls.

\section{Exclusion criteria}

Critically ill clients (unconscious state), women delivering congenital malformed babies, mental illness clients and women with no antenatal card or documented anthropometric measures.

\section{Sample size and Sampling}

A sample of 216 was calculated using modified Kesley formula for case control study. Purposive sampling method was used in which Cases were 72, they were those who delivered babies of weight $\geq$ $4000 \mathrm{~g}$ while Controls were 144 and they delivered babies of weight $2500 \mathrm{~g}$ to $3500 \mathrm{~g}$.

\section{Data collection methods and tools}

The weight of the mother was measured by a weighing balance with a sensitivity of $100 \mathrm{~g}$ and height of the mother was measured using a calibrated height measuring steel attached to the beam balance and recorded to $0.1 \mathrm{~cm}$, mothers were required to maintain an upright position with their feet together, and a 
horizontal headpiece was lowered onto the women's head. Maternal weight gain was measured by subtracting the weight before pregnant from the last measured weight before delivery.

The Reproductive and Child Health card ( $\mathrm{RCH}$ ) was checked to obtain weight of the mother at the first and last antenatal visit. Body Mass Index (BMI) was calculated using preconception maternal weight reported by mothers in Kilograms dividing by maternal height in meters squared. Maternal random/fasting blood glucose (RBG/FBG) was measured by ACCU-Check Active meter by a drop of capillary blood obtained by finger prick. A modified World Health Organization criteria to diagnose diabetes mellitus during pregnancy was used. All women with a Fasting plasma glucose level of $\geq 7.0 \mathrm{mmol} / \mathrm{l}(126 \mathrm{mg} / \mathrm{dl})$ or a 2 -hour plasma glucose of $\geq 11.1 \mathrm{mmol} / \mathrm{l}(200 \mathrm{mg} / \mathrm{dl})$ and those who are known diabetic were considered as women with diabetes during pregnancy [16]. A 2-hour oral Glucose Tolerance Test (OGTT) was used.

\section{Data collection procedure}

Soon after delivery, participants were categorized as cases or controls. The weight of the newborn was measured soon after delivery using a beam balance accurate to $100 \mathrm{~g}$. Questionnaires were used to obtain data and were checked for clarity before data analysis. Questionnaire was adopted from previous studies [7], [17], [18].

This was an unmatched case control design. In a situation where the case never met the inclusion criteria, the next woman who delivered an infant with birth weight of $\geq 4000 \mathrm{~g}$ was recruited. In a case, whereby two consecutive women delivered infants with birth weight 4000 grams and above, the next four women who delivered infants with normal birth weights ( 2500 grams to 3500 grams) were recruited.

\section{Data analysis}

All statistical analysis was performed using SPSS, version 25.0 (IBM Inc., Chicago). Categorical variables were summarized as the frequency with percentages. The $\mathrm{p}$-value, OR, and $95 \%$ confidence interval were tested to determine the predictors of macrosomia. A p-value of $<0.05$ was considered to be significant for all statistical tests. Factors with significant odds ratio $(O R)$ were subjected to multi variable logistic regression to determine the adjusted odds ratio (AOR).

\section{Validity of Data and reliability of Data}

To ensure the validity of the data, the weighing scales were being checked after every measurement of the newborn for zero error. Tools were pre-tested at Iringa Regional Referral Hospital. This was done before the actual data collection to test the practicality and accuracy of the tools, to yield valid information. The strict research guidelines for data collection and data analysis were adhered to in order to enhance reliability.

\section{Ethical Consideration}


Ethical clearance to conduct the study was sought from the University of Dodoma directorate of research and publication. Permission to conduct the study at the study site was obtained from medical officer in charge at Iringa Regional Referral hospital.

A written informed consent was obtained from study participants before enrollment. Confidentiality was ensured and identification number was used to identify the study participants. Regardless of their study participation all patients received treatment according to hospital protocol. Participants who never consented and those who were not eligible for the study were attended by the investigator as part of routine clinical duties

\section{Results}

A total of 216 participants were involved in this study. The mean age of study participants was 28.46 years and standard deviation of 6.00 . Majority $116(53.70 \%)$ of respondents were between the age 25 34 years of which $44(61.11 \%)$ were cases and $72(50 \%)$ were controls. Regarding parity, $78(33.80 \%)$ of study participants were primiparous in which 15 (20.83\%) were cases and 58 (40.28) were controls. As shown in Table I.

Considering gestation age, majority of study participants $132(61.11 \%)$ delivered at a gestation age of 37 - 39 weeks of which 17 (23.63\%) were cases and 115 (79.86\%) were controls. Consider Table I.

Table I: Social Demographic characteristics of study participants at Iringa Regional Referral Hospital $(\mathrm{N}=216)$ 


\begin{tabular}{|llll|}
\hline Variable & Total & Cases & Control \\
& $\mathbf{N}=\mathbf{2 1 6}$ & $\mathbf{n = 7 2}$ & $\mathbf{n = 1 4 4}$ \\
& $\mathbf{N}(\%)$ & $\mathbf{n}(\%)$ & $\mathbf{n}(\%)$ \\
\hline Child's Particulars & & & \\
\hline Sex & & & \\
\hline Male & $124(57.41)$ & $45(62.50)$ & $79(54.86)$ \\
\hline Female & $92(42.59)$ & $27(37.50)$ & $65(54.14)$ \\
\hline Maternal Particulars & & & \\
\hline Maternal age (Years) & & & \\
\hline $15-24$ & $64(29.63)$ & $11(15.28)$ & $53(36.81)$ \\
\hline $25-34$ & $116(53.70)$ & $44(61.11)$ & $72(50.00)$ \\
\hline $35+$ & $36(16.67)$ & $17(23.61)$ & $19(13.19)$ \\
\hline Residence & & & \\
\hline Rural & & & \\
\hline Urban & $94(43.52)$ & $30(41.67)$ & $64(44.44)$ \\
\hline Parity & $122(56.48)$ & $42(58.33)$ & $80(55.56)$ \\
\hline 1 & & & \\
\hline 2 & $73(33.80)$ & $15(20.83)$ & $58(40.28)$ \\
\hline 3 & $66(30.56)$ & $19(26.39)$ & $47(32.64)$ \\
\hline $4+$ & $44(20.37)$ & $18(25.00)$ & $26(18.06)$ \\
\hline Gestation age (weeks) & & & \\
\hline $37-39$ & $132(61.11)$ & $17(23.61)$ & $115(79.86)$ \\
\hline 40 - 41(+6 days) & $68(31.48)$ & $45(62.50)$ & $23(15.97)$ \\
\hline $42+$ & $16(7.14)$ & $10(13.89)$ & $6(4.17)$ \\
\hline Level of education & & & \\
\hline No formal education & $34.78)$ & $13(16.67)$ & $22(15.28)$ \\
\hline Primary & & & \\
\hline
\end{tabular}

The predictors of fetal macrosomia among women delivering at Iringa regional referral hospital. 
This study found that, among the maternal factors, gestation age $\geq 40$ weeks ( $p$-value $=<0.0001$ ), a previous history of macrosomic baby ( $p$-value $=<0.0001)$, diabetes mellitus in pregnancy, higher parity $(p$-value $=<0.0001)$ and advanced maternal age $(p$-value $=0.0028)$ were predictors of fetal macrosomia on cross tabulation as shown in Table III.

Table III: Predictors of fetal macrosomia among women delivering at Iringa regional referral hospital $(\mathrm{N}=216)$ 


\begin{tabular}{|c|c|c|c|c|}
\hline Variable & Macrosomia & & & \\
\hline Case & Control & $x^{2}$ & P-value & \\
\hline$n=72$ & $n=144$ & & & \\
\hline \multicolumn{5}{|l|}{ Child's characteristics } \\
\hline Sex & & & $1.1455^{\mathrm{a}}$ & 0.2845 \\
\hline Male & $45(62.50)$ & $79(54.86)$ & & \\
\hline Female & $27(37.50)$ & $65(45.14)$ & & \\
\hline \multicolumn{5}{|l|}{ Maternal factors } \\
\hline Age & & & $11.7363^{\mathrm{a}}$ & 0.0028 \\
\hline $15-24$ & $11(15.28)$ & $53(36.81)$ & & \\
\hline $25-34$ & $44(61.11)$ & $72(50.00)$ & & \\
\hline $35+$ & $17(23.61)$ & 19(13.19) & & \\
\hline Residence & & & $0.1507^{a}$ & 0.6979 \\
\hline Rural & $30(41.67)$ & $64(44.44)$ & & \\
\hline Urban & $42(58.33)$ & $80(55.56)$ & & \\
\hline Gestation age & & & $63.9846^{\mathrm{a}}$ & $<.0001$ \\
\hline $37-39$ & $17(23.61)$ & $115(79.86)$ & & \\
\hline 40 - 41(+6 days) & $45(62.50)$ & $23(15.97)$ & & \\
\hline $42+$ & 10(13.89) & $6(4.17)$ & & \\
\hline Maternal Body Mass Index $\left(\mathrm{kg} / \mathrm{m}^{2}\right)$ & & & $0.8827^{a}$ & 0.6432 \\
\hline $18.5-24.9$ & $27(37.50)$ & $51(35.42)$ & & \\
\hline $25.0-29.90$ & $27(37.50)$ & $59(40.97)$ & & \\
\hline$\geq 30.0$ & $18(25.00)$ & $30(20.83)$ & & \\
\hline Previous history of delivery Macrosomia & & & $30.4912^{a}$ & $<.0001$ \\
\hline Yes & $35(48.61)$ & $20(13.89)$ & & \\
\hline No & $37(51.39)$ & 124(86.11) & & \\
\hline Diabetes Mellitus & & & & $<.0001^{*}$ \\
\hline Diabetic & 10(13.89) & $1(0.69)$ & & \\
\hline
\end{tabular}




\begin{tabular}{|lllll|}
\hline Parity & & & $18.1653^{\mathrm{a}}$ & $<.0001$ \\
\hline 1 & $15(28.38)$ & $58(40.28)$ & & \\
\hline 2 & $19(26.39)$ & $47(32.64)$ & & \\
\hline $4+$ & $18(25.00)$ & $26(18.06)$ & & \\
\hline Weight gain during pregnancy & $20(27.78)$ & $13(9.03)$ & & 0.3818 \\
\hline$\leq 11$ & & & 0.7648 & \\
\hline$>11$ & $38(52.78)$ & $85(59.03)$ & & \\
\hline
\end{tabular}

\section{P-Value with * indicate p-value of Fisher exact test}

Predictors of fetal macrosomia among women delivering at Iringa regional referral hospital $(n=216)$.

In this study, women with advanced gestation age ( $\geq 40$ weeks) were 8 times more likely to give birth to a macrosomic baby compared to women who delivered at a gestation age of 37 to 39 weeks (AOR=8.10, $95 \% \mathrm{Cl}=3.66-17.91, p=<0.0001)$. Women with Diabetic mellitus were 14 times more likely to give birth to a macrosomic baby compared to women without diabetes mellitus (AOR=14.94, 95\% $\mathrm{Cl}=1.60-39.91$, $p=0.0178$ ) as shown in Table IV.

Table IV: Logistic Regression of Factors associated with fetal macrosomia at Iringa Regional Referral Hospital ( $\mathrm{N}=216)$ 


\begin{tabular}{|c|c|c|c|c|c|c|c|c|}
\hline \multirow[t]{2}{*}{ Variable } & OR & $\begin{array}{l}95 \% \\
\mathrm{Cl}\end{array}$ & $\begin{array}{l}\mathrm{P}- \\
\text { value }\end{array}$ & \multirow[t]{2}{*}{ AOR } & $\begin{array}{l}95 \% \\
\mathrm{Cl}\end{array}$ & \multirow[t]{2}{*}{$\begin{array}{l}\mathrm{P}- \\
\text { value }\end{array}$} & & \\
\hline & & \multicolumn{2}{|l|}{ OR } & & AOR & & & \\
\hline Lower & Upper & Lower & Upper & & & & & \\
\hline \multicolumn{9}{|l|}{ Maternal Age } \\
\hline $15-24$ & Ref. & & & & & & & \\
\hline $25-34$ & 2.94 & 1.39 & 6.23 & 0.0048 & 1.75 & 0.65 & 4.71 & 0.2666 \\
\hline$\geq 35$ & 4.31 & 1.72 & 10.84 & 0.0019 & 1.04 & 0.26 & 4.234 & 0.9584 \\
\hline \multicolumn{9}{|l|}{ Gestation age } \\
\hline $37-39$ & Ref. & & & & & & & \\
\hline 40 - 41(+6 days) & 13.24 & 6.47 & 27.07 & $<0.0001$ & 8.10 & 3.66 & 17.91 & $<0.0001$ \\
\hline$\geq 42$ & 11.28 & 3.63 & 35.01 & $<0.0001$ & 8.67 & 2.53 & 29.74 & 0.0006 \\
\hline \multicolumn{9}{|l|}{ Parity } \\
\hline 1 & Ref. & & & & & & & \\
\hline 2 & 1.56 & 0.72 & 3.41 & 0.2608 & 1.02 & 0.38 & 2.75 & 0.9713 \\
\hline 3 & 2.68 & 1.17 & 6.12 & 0.0196 & 1.47 & 0.47 & 4.60 & 0.5072 \\
\hline $4+$ & 5.95 & 2.42 & 14.63 & 0.0001 & 1.78 & 0.46 & 6.94 & 0.4068 \\
\hline \multicolumn{9}{|l|}{$\begin{array}{l}\text { History of delivery } \\
\text { Macrosomia }\end{array}$} \\
\hline No & Ref. & & & & & & & \\
\hline Yes & 5.87 & 3.03 & 11.36 & $<0.0001$ & 2.34 & 0.90 & 6.09 & 0.0815 \\
\hline \multicolumn{9}{|l|}{ Diabetes mellitus } \\
\hline Non-diabetic & Ref. & & & & & & & \\
\hline Diabetic & 0.04 & 0.01 & 0.35 & 0.0031 & 14.94 & 1.60 & 39.91 & 0.0178 \\
\hline
\end{tabular}

\section{Discussion}

The identified predictors of fetal macrosomia in this study are advanced gestation age and diabetes mellitus during pregnancy. Maternal BMI, parity, weight gain during pregnancy, age of participant, previous history of macrosomic baby delivery and child's gender were not significantly associated with fetal macrosomia. 
In Taiwan and Indonesia, fetal macrosomia has been strongly associated with overweight and obesity [19], [20]. This is contrary to the finding in this study in which body mass index didn't predict occurrence of fetal macrosomia. Although not statistically significant, excessive weight gain before and during pregnancy have been linked to decreasing insulin sensitivity which facilitates transfer of glucose via the placenta to the growing fetus hence leading to increasing fetal size or macrosomia [21], [22]. The difference can be due to study designs in which the studies in Taiwan and Indonesia used a cohort study design while this was a control study.

The predictors of fetal macrosomia in Malaysia include increasing maternal age, increasing body mass index (BMI), increasing weight gain during pregnancy, higher parity and diabetes mellitus during pregnancy [23]. This is contrary to the findings of this study in which advanced maternal age, maternal body mass index, maternal weight gains during pregnancy and higher parity were not associated with fetal macrosomia although diabetes mellitus during pregnancy was strongly associated with macrosomia. The differences in study duration and methodology can explain why findings differ although diabetes mellitus during pregnancy leads to increasing fetal adiposity and hence exposing a fetus into developing fetal macrosomia [24].

In Cameroon, predictors identified included a previous history of macrosomic delivery, maternal weight gain above $16 \mathrm{~kg}$, higher parity, male gender and advanced gestation age [25]. Comparing to this study, only advanced gestation age is a similar factor identified while previous history of delivering macrosomic baby, higher parity, male gender and maternal weight gain were not associated with fetal macrosomia in this study. According to a study done in Sydney, it was estimated that a fetus gains $176.5 \mathrm{~g}$ per week, this can explain why advanced gestation age predisposes a woman to deliver a macrosomic baby [26].

Macrosomia in Chad and Ghana has been associated with a previous history of delivering macrosomic baby (Bray Madoue et al., 2018 \& Bedu-Addo et al., 2020). Although it was not significant in this study, a previous history of delivering a macrosomia baby predisposes a woman to increasing body mass index during conception and excessive weight gain during pregnancy, this leads to fetal macrosomia.

In Hawassa city, Ethiopia, male gender, advanced gestation age and having a previous history of macrosomia baby delivery were significant predictors of fetal macrosomia [28] while in this study, advanced gestation age was a strong factors associated with fetal macrosomia. Male gender was not associated with fetal macrosomia in this study. Male gender of the fetus has been linked to fetal macrosomia and this is explained by the effect of sexual dimorphism in relation to maternal glucose intolerance and birth weight [29].

In Mekelle city, Tigray, Ethiopia in which women with a history of a previous macrosomic delivery were 3 times more likely to give birth to a macrosomia baby compared to women with no history [18], in this study women with a previous history of macrosomic delivery were not significantly associated with fetal macrosomia. In Ethiopia women who were aged 30 years and above were 2.6 times to delivery macrosomia baby compared to those who were less than 30 years [18]. Although not statistically 
significant in this study, advanced maternal age has been linked to increasing metabolism that leads to increasing growth of the fetus.

In Tanzania, a study done at Muhimbili National Hospital, the predictors of fetal macrosomia were increasing maternal weight above $80 \mathrm{~kg}$, advanced maternal age of 30 - 39 years, multiparty, diabetes mellitus during pregnancy and a previous history of delivering a macrosomic baby [7]. In this study done at advanced gestation age and diabetes mellitus during pregnancy were significantly associated with fetal macrosomia. Increasing maternal weight gain, a previous history of macrosomic baby delivery, advanced maternal age and multiparty were not associated with fetal macrosomia.

\section{Study limitations}

There were challenges for participants to recall preconception weight. To minimize this error, the study included participants who were able to recall weight before pregnancy.

In this study diabetes mellitus was diagnosed by a WHO criteria which didn't involve follow up of women from $24-28$ weeks of gestation age. 


\begin{tabular}{|c|c|c|c|c|c|c|c|c|}
\hline \multirow[t]{2}{*}{ Variable } & OR & $\begin{array}{l}95 \% \\
\mathrm{Cl}\end{array}$ & $\begin{array}{l}\mathrm{P}- \\
\text { value }\end{array}$ & AOR & $\begin{array}{l}95 \% \\
\mathrm{Cl}\end{array}$ & $\begin{array}{l}\mathrm{P} \text { - } \\
\text { value }\end{array}$ & & \\
\hline & & \multicolumn{3}{|l|}{ OR } & \multicolumn{2}{|l|}{ AOR } & & \\
\hline Lower & Upper & Lower & Upper & & & & & \\
\hline \multicolumn{9}{|l|}{ Maternal Age } \\
\hline $15-24$ & Ref. & & & & & & & \\
\hline $25-34$ & 2.94 & 1.39 & 6.23 & 0.0048 & 1.75 & 0.65 & 4.71 & 0.2666 \\
\hline$\geq 35$ & 4.31 & 1.72 & 10.84 & 0.0019 & 1.04 & 0.26 & 4.234 & 0.9584 \\
\hline \multicolumn{9}{|l|}{ Gestation age } \\
\hline $37-39$ & Ref. & & & & & & & \\
\hline $40-41$ (+6 days) & 13.24 & 6.47 & 27.07 & $<0.0001$ & 8.10 & 3.66 & 17.91 & $<0.0001$ \\
\hline$\geq 42$ & 11.28 & 3.63 & 35.01 & $<0.0001$ & 8.67 & 2.53 & 29.74 & 0.0006 \\
\hline \multicolumn{9}{|l|}{ Parity } \\
\hline 1 & Ref. & & & & & & & \\
\hline 2 & 1.56 & 0.72 & 3.41 & 0.2608 & 1.02 & 0.38 & 2.75 & 0.9713 \\
\hline 3 & 2.68 & 1.17 & 6.12 & 0.0196 & 1.47 & 0.47 & 4.60 & 0.5072 \\
\hline $4+$ & 5.95 & 2.42 & 14.63 & 0.0001 & 1.78 & 0.46 & 6.94 & 0.4068 \\
\hline \multicolumn{9}{|l|}{$\begin{array}{l}\text { History of delivery } \\
\text { Macrosomia }\end{array}$} \\
\hline No & Ref. & & & & & & & \\
\hline Yes & 5.87 & 3.03 & 11.36 & $<0.0001$ & 2.34 & 0.90 & 6.09 & 0.0815 \\
\hline \multicolumn{9}{|l|}{ Diabetes mellitus } \\
\hline Non-diabetic & Ref. & & & & & & & \\
\hline Diabetic & 0.04 & 0.01 & 0.35 & 0.0031 & 14.94 & 1.60 & 39.91 & 0.0178 \\
\hline
\end{tabular}

\section{Conclusion}

The factors which were associated with fetal macrosomia in the current study were; advanced maternal gestation age $\geq 40$ weeks and diabetes mellitus during pregnancy.

\section{Declarations}

Funding: No funding was received 
Conflict of interest: The authors declare no conflict of interest.

Availability of data and material: All research data and materials are available upon request

Ethical statement

Ethical statement was obtained from the University of Dodoma, Directorate of Research. Copies were sent to Iringa Regional Referral Hospital management for approval.

\section{Consent}

A complete description of the aims of the study, informed consent of participants, and confidentiality of the information sources were ensured. For participants who were below 18 years of age, consent was requested from the legal guardian/parent.

\section{Declaration and copyright}

I, Emmanuel Imani Ngadaya, declare that this research is my own original work and that it has not been presented, published or shared to any other professional for other purposes apart from academic purposes.

\section{Acknowledgements}

I thank all study participants for their willingness to participate in this study.

\section{Abbreviations}

IRRH

DM

$\mathrm{NICU}$

WHO

ANC

OGTT

LNMP

$\mathrm{RCH}$
Iringa Regional Referral Hospital

Diabetes Mellitus

Neonatal Intensive Care Unit

World Health Organization

Antenatal Clinic

Oral Glucose Tolerance Test

Last Normal Menstrual Period

Reproductive and Child Health

\section{References}


[1] J. Ye et al., "Searching for the definition of macrosomia through an outcome-based approach in low- and middle-income countries: A secondary analysis of the WHO Global Survey in Africa, Asia and Latin America," BMC Pregnancy Childbirth, vol. 15, no. 1, pp. 1-10, 2015, doi: 10.1186/s12884-015-0765$\mathrm{z}$.

[2] M. C. Dennedy and F. Dunne, "Macrosomia: Defining the problem worldwide," Lancet, vol. 381, no. 9865, pp. 435-436, 2013, doi: 10.1016/S0140-6736(12)62090-X.

[3] ACOG, "Clinical Management Guidelines for Obstetrician - Gynecologists," Obstet. Gynecol., vol. 133, no. 76, pp. 168-186, 2019.

[4] L. J. Black MH, Sacks DA, Xiang AH, "The relative contribution of prepregnancy overweight and obesity, gestational weight gain, and IADPSG-defined gesta- tional diabetes mellitus to fetal overgrowth," Diabetes Care, vol. 36, pp. 56-62, 2013, doi: 10.2337/dc12-0741.

[5] C. A. Asplund, "1543-1410-1-SM.pdf," pp. 550-554, 2008, doi: 10.1370/afm.903.INTRODUCTION.

[6] G. Pagani, N. Palai, S. Zatti, N. Fratelli, F. Prefumo, and T. Frusca, "Fetal weight estimation in gestational diabetic pregnancies: Comparison between conventional and three-dimensional fractional thigh volume methods using gestation-adjusted projection," Ultrasound Obstet. Gynecol., vol. 43, no. 1, pp. 72-76, 2014, doi: 10.1002/uog.12458.

[7] A. S. Said and K. P. Manji, "Risk factors and outcomes of fetal macrosomia in a tertiary centre in Tanzania: A case-control study," BMC Pregnancy Childbirth, vol. 16, no. 1, pp. 1-8, 2016, doi: 10.1186/s12884-016-1044-3.

[8] R. N. Akindele, L. I. Audu, and O. A. Mokuolu, "Macrosomic births in Abuja: A case-control study of predisposing factors and early neonatal outcome," Niger. J. Clin. Pract., vol. 20, no. 3, pp. 320-327, 2017, doi: 10.4103/1119-3077.196060.

[9] K. Bedu-Addo et al., "Prevalence and associated factors of fetal macrosomia in a rural community in Ghana," Cogent Med., vol. 7, no. 1, 2020, doi: 10.1080/2331205x.2020.1746602.

[10] M. Thorsell, M. Kaijser, H. Almström, and E. Andolf, "Large fetal size in early pregnancy associated with macrosomia," Ultrasound Obstet. Gynecol., vol. 35, no. 4, pp. 390-394, 2010, doi: 10.1002/uog.7529.

[11] R. Cunningham FG, Levenok K, Cunningham FG, Levenok K, Rouse, Macrosomia. In: Williams Obstretrics. 24rd edition. McGraw Hill; 2013. p. 1325-40. McGraw Hill, 2013.

[12] V. L. Bandika, F. N. Were, E. D. Simiyu, and D. P. Oyatsi, "Hypoglycaemia and hypocalcaemia as determinants of admission birth weight criteria for term stable low risk macrosomic neonates," Afr. Health Sci., vol. 14, no. 3, pp. 510-516, 2014, doi: 10.4314/ahs.v14i3.3. 
[13] M. H. K. Maher, R. Soltani, A. H. Zeinalzadeh, and S. Pourasghar, "Complications and risk factors of neonatal macrosomia: A case-control study," Iran. J. Neonatol., 2018.

[14] C. Kadji, M. M. Cannie, S. Resta, and D. Guez, "Expert Review Magnetic resonance imaging for prenatal estimation of birthweight in pregnancy: review of available data, techniques, and future perspectives," Am. J. Obstet. Gynecol., 2019, doi: 10.1016/j.ajog.2018.12.031.

[15] G. L. Malin, G. J. Bugg, Y. Takwoingi, and J. G. Thornton, "Antenatal magnetic resonance imaging versus ultrasound for predicting neonatal macrosomia: a systematic review and meta-analysis," no. March, pp. 77-88, 2016, doi: 10.1111/1471-0528.13517.

[16] WHO/IDF, "definition and diagnosis of diabetes mellitus and intermediate hyperglycemia RepoRt of a WHo/IDf Consultatlon," 2006.

[17] M. A. Alsammani and S. R. Ahmed, "Fetal and maternal outcomes in pregnancies complicated with fetal macrosomia," N. Am. J. Med. Sci., vol. 4, no. 6, pp. 283-286, 2012, doi: 10.4103/1947-2714.97212.

[18] F. G. Tela, A. M. Bezabih, A. K. Adhanu, and K. B. Tekola, "Fetal macrosomia and its associated factors among singleton live-births in private clinics in Mekelle city, Tigray, Ethiopia," BMC Pregnancy Childbirth, vol. 19, no. 1, pp. 1-6, 2019, doi: 10.1186/s12884-019-2379-3.

[19] T. H. Hung and T. T. an. Hsieh, "Pregestational body mass index, gestational weight gain, and risks for adverse pregnancy outcomes among Taiwanese women: A retrospective cohort study," Taiwan. J. Obstet. Gynecol., vol. 55, no. 4, pp. 575-581, 2016, doi: 10.1016/j.tjog.2016.06.016.

[20] H. Soltani, N. I. Lipoeto, F. J. Fair, K. Kilner, and Y. Yusrawati, “Pre-pregnancy body mass index and gestational weight gain and their effects on pregnancy and birth outcomes: A cohort study in West Sumatra, Indonesia," BMC Womens. Health, vol. 17, no. 1, pp. 1-12, 2017, doi: 10.1186/s12905-017-04552.

[21] T. Pongcharoen, S. Gowachirapant, P. Wecharak, N. Sangket, and P. Winichagoon, "Pre-pregnancy body mass index and gestational weight gain in Thai pregnant women as risks for low birth weight and macrosomia," Asia Pac. J. Clin. Nutr., 2016, doi: 10.6133/apjcn.092015.41.

[22] M. H. Vickers, "Developmental programming and transgenerational transmission of obesity," Ann. Nutr. Metab., vol. 64, no. SUPPL.1, pp. 26-34, 2014, doi: 10.1159/000360506.

[23] H. Yadav and N. Lee, "Factors influencing macrosomia in pregnant women in a tertiary care hospital in Malaysia," J. Obstet. Gynaecol. Res., vol. 40, no. 2, pp. 439-444, 2014, doi: 10.1111/jog.12209.

[24] A. W. Mwanri, Gestational diabetes mellitus in Tanzania - public health perspectives. 2015.

[25] E. Nkwabong and G. R. Nzalli Tangho, "Risk Factors for Macrosomia," J. Obstet. Gynecol. India, vol. 65, no. 4, pp. 226-229, 2015, doi: 10.1007/s13224-014-0586-4. 
[26] M. Mongelli, R. Benzie, and G. Condous, "Average fetal weekly weight gain: A novel measure of fetal growth velocity," J. Matern. Neonatal Med., vol. 29, no. 4, pp. 676-679, 2016, doi: 10.3109/14767058.2015.1015981.

[27] G. Bray Madoue, S. Nguele Sile, F. Lhagadang, and A. Saleh, "Foetal macrosomia: risk factors, maternal and foetal outcome in N'Djamena mother and child hospital, Chad," Obstet. Gynecol. Int. J., vol. 9, no. 3, pp. 40-43, 2018, doi: 10.15406/ogij.2018.09.00322.

[28] A. K. Biratu, N. Wakgari, and B. Jikamo, "Magnitude of fetal macrosomia and its associated factors at public health institutions of Hawassa city, southern Ethiopia," BMC Res. Notes, vol. 11, no. 1, pp. 1-6, 2018, doi: 10.1186/s13104-018-4005-2.

[29] W. Ricart et al., "Maternal glucose tolerance status influences the risk of macrosomia in male but not in female fetuses," J. Epidemiol. Community Health, vol. 63, no. 1, pp. 64-68, 2009, doi: 10.1136/jech.2008.074542. 